\title{
An examination of environmental correlates with childhood height-for-age in Ghana
}

\author{
Ebenezer Nikoi ${ }^{1, *}$ and Peter Anthamatten ${ }^{2}$ \\ 'Department of Geography, University of Minnesota, 414 Social Sciences Building, 267 19th Avenue South, \\ Minneapolis, MN 55455, USA: ${ }^{2}$ Department of Geography and Environmental Sciences, Auraria Campus, \\ Denver, CO, USA
}

Submitted 25 June 2011: Final revision received 22 February 2012: Accepted 30 March 2012: First published online 21 May 2012

\begin{abstract}
Objective: The relationship between a child's environment and nutritional status is difficult to examine yet could offer an important guide to policy. The objective of the present work was to examine individual and environmental correlates with childhood height-for-age in Ghana.

Design: Data were derived from the 2008 MEASURE Demographic and Health Survey in Ghana, the 2000 Ghana Population and Housing Census, and the World Wide Fund for Nature's eco-regions database. A generalized linear mixed regression model was used to estimate the effects of individual and environmental correlates on height-for-age.

Subjects: The study examined 2225 Ghanaian children aged 0-59 months.

Setting: The setting was all districts in Ghana for the year 2008.

Results: After accounting for individual characteristics of children, mothers and households, height-for-age was significantly associated with population density. Other significantly associated variables in the final model were the age of the child, vaccination status, the size of the child at birth, months of breast-feeding, mother's BMI, whether the child's mother had health insurance and wealth quintile. Conclusions: In addition to a number of characteristics of the children and their households, the social milieu is important to understanding differences in heightfor-age among children in Ghana. The biophysical environment was not associated with height-for-age.
\end{abstract}

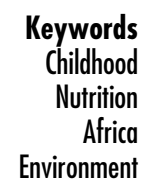

Malnutrition, defined here as 'a cellular imbalance between the supply of nutrients and energy and the demand for them to ensure growth, maintenance, activity, and specific functions, ${ }^{,(1)}$, continues to be a significant challenge for children in low-income countries, particularly in Africa. Undernutrition remains one of Africa's most fundamental challenges for improving human development. UNICEF defines 'undernutrition' as ${ }^{(2)}$ :

the outcome of insufficient food intake and repeated infectious diseases. It includes being underweight for one's age, short for one's age (stunted), thin for one's height (wasted) and deficient in vitamins and minerals (micronutrient malnutrition).

Because the time and capacities of caregivers are limited, many children on the continent are unable to access or effectively utilize the food and health services they need for a healthy life ${ }^{(3)}$. According to UNICEF estimates, nearly one-third of all sub-Saharan African children under 5 years of age are underweight ${ }^{(4)}$; that is, below -2 standard deviations from the median weight-for-height in a global reference population.
Ghana ratified the United Nations Convention on the Rights of the Child (UNCRC) in 1990 and demonstrated its commitment by launching a 10-year National Program of Action in 1992. This programme translated the UNCRC document into six major Ghanaian languages, reformed laws related to children, initiated compulsory and universal basic education, and created the Ministry for Women and Children. These initiatives contributed to increased school enrolment (particularly for girls) and improved immunization rates. Results from five Ghana Demographic and Health Surveys (GDHS) document subsequent improvements in infant and childhood mortality rates $^{(5)}$.

Many national governments do not have the financial resources necessary to achieve the nutrition goals prescribed by the UNCRC. Sadly, many also lack the appropriate knowledge and political will to ensure progress in implementing measures that are financially feasible. Providing specific information at different scales can enable more cost-effective and efficient ways to address child nutritional deficits. Research is not necessary to demonstrate that impoverished children who lack quality 
shelter, diet, education and health care are especially vulnerable to malnutrition. Research can however identify the people and places with the greatest need, enhance our understanding of the variables that best explain children's failure to thrive in particular situations and guide interventions that could improve children's well-being.

Some scholarship, particularly by climatologists, biologists, ecologists and soil scientists, focuses on the biophysical environment, but few make the connection to nutritional well-being ${ }^{(6,7)}$. Work that examines this connection shows that the biophysical environment has important implications for children's nutritional outcomes, through its impact on the potential for agricultural sustainability and food production, but evidence is inconclusive. Factors such as rainfall and soil type are among the biophysical environmental conditions that impact the quantity, quality and diversity of food produced. Poor nutritional status has been linked to the altitudes at which children reside in Tibet $^{(8)}$ for example, and the influence of ecology on nutrition and body composition measures has been cited as a reason for significant group differences among pre-school children in coastal, Himalayan and desert ecology regions in India ${ }^{(9)}$. In West Africa, the most serious child malnutrition occurs in more arid regions, where drought-resistant crops dominate, while the least malnourished children are in the more humid areas where root crops are dominant ${ }^{(10)}$. The nature of large-scale measurements such as biophysical environment makes them highly susceptible to error that requires careful examination of the links between these contexts and children's nutritional outcome. Several studies have found household variables to explain more variation in child hunger in the developing world context than environmental factors ${ }^{(11,12)}$.

Dickinson et $a l^{(13)}$ propose that environmental factors be combined with social factors to help rural communities confront the barriers to improving their intake of micronutrients, such as $\mathrm{Fe}$ and $\mathrm{Zn}$. The current research assessed factors associated with children's differential nutritional status, as indicated by height-for-age, in Ghana. Two related questions of both scholarly and practical significance are addressed in the analysis reported here:

1. What characteristics of children, mothers and households are associated with height-for-age among children in Ghana?

2. After accounting for associated factors for children, mothers and households, do the socio-economic and biophysical characteristics of the place where children reside provide additional explanation for observed differences in height-for-age?

The goal of the work was to examine individual and environmental correlates with difference in childhood height-for-age in Ghana.

\section{Methods}

\section{Data sources}

The MEASURE Demographic and Health Surveys (DHS) are recognized as an accurate source of nationally representative information about the demographic and health status of low-income countries, with an emphasis on young children and their mothers. Selection of the DHS stratified sample for every survey entails two stages. Enumeration areas ${ }^{(14)}$, or population clusters, based on the national census, are randomly selected with probability proportional to the number of households. After the list of households in each of the selected enumeration areas has been updated, households are randomly selected with equal probability for interview ${ }^{(15)}$. Standardized modules are used to construct questionnaires for each national survey. More detailed information about the specifics of the DHS sampling and data collection methods can be found at its website (http://www.measuredhs.com/).

What is remarkable about DHS data - in contrast to national census data, for example - is that variables are reported for individuals and their households. This enables multivariate analysis at the level of the individual child. The individual child is the most logical unit of analysis for research on childhood malnutrition, since it is he or she who consumes food, experiences infectious diseases and exhibits a particular nutritional status.

In the most recent GDHS conducted in 2008, 412 enumeration areas were randomly selected from a list based on the 2000 Ghana Population and Housing Census (PHC). Interviews were conducted in 11778 households, yielding a response rate of $97 \%$ for women and $96 \%$ for men ${ }^{(5)}$. These samples are representative for Ghana as a whole, for urban and rural areas, and for the country's ten official regions.

The present study also uses data from the 2000 Ghana PHC. In 2000, the Ghana PHC collected census information on both population and housing for the first time. The census was carried out by the Ghana Statistical Service and covered all persons in households and all living quarters in Ghana at midnight of Census Night (26 March 2000). Ecological zone classifications are derived from the World Wide Fund for Nature's classification system ${ }^{(16)}$, built from careful research designed to represent natural conditions without human intervention ${ }^{(17)}$. According to this regionalization, Ghana straddles three major habitat biomes that are subdivided into five ecological zones. These are Eastern Guinea Forest, West Sudanian Savannah, Guinea Forest-Savannah Mosaic, Central African Mangroves and Guinea Mangroves. These zones are not congruent with districts or regional boundaries in Ghana.

\section{Outcome variable}

Height-for-age refers to the expected height of a healthy child, given a child's age. This measure can be used as a measure of long-term adequacy of consumption of 
nutrients, especially protein. An individual child's stature may result from genetic characteristics, low birth weight (also the result of a complex interaction of numerous variables) or infectious disease. Low height-for-age, often called stunting, can be interpreted as an indication of poor nutritional status, a common practice in public health and nutrition research ${ }^{(18-21)}$.

Height-for-age data for Ghana were captured by the GDHS, with children ranging from 5.68 standard deviations below the population mean $(-5.68 \mathrm{sD})$ to 5.96 standard deviations above the mean $(+5.96 \mathrm{SD})$. Traditionally, stunting and wasting were defined in relation to a comparison population in a high-income country in the same region, based on the assumption that ethnically similar populations are also genetically similar, manifested in characteristics such as height and weight ${ }^{(22)}$. More recently, the WHO has argued that, under optimal conditions, growth is the same for all populations ${ }^{(23)}$. It has therefore issued standards that can be applied to young children worldwide. The use of National Center for Health Statistics/WHO reference standards makes the findings from the present study comparable to previous studies in Ghana and elsewhere. Additional information about international growth standards is available at the WHO website (http://www.who.int/childgrowth/en/).

\section{Exposure variables}

Scholarly research has shown that a large number of variables are associated with child nutritional outcomes $^{(11,18-21,24,25)}$. We surveyed the literature to determine the variables to include in our analysis. The variables selected included characteristics of the child, including age of the child ${ }^{(26,27)}$, sex of the child ${ }^{(20,28)}$, vaccination status ${ }^{(29)}$, size of the child at birth ${ }^{(20)}$ and months of breast-feeding ${ }^{(30)}$. Additionally, facets of the child's mother and household are related to a child's risk for malnutrition; these included mother's education $^{(19,31)}$, mother's age at first childbirth ${ }^{(21)}$, mother's BMI ${ }^{(32)}$, whether the mother has insurance, size of the household ${ }^{(33)}$, ethnicity and poverty ${ }^{(34-36)}$.

Poverty is often regarded as the single most important determinant of health ${ }^{(34)}$. Poverty is frequently estimated from household income figures. Unfortunately, these figures are often misleading measures of wealth because the data are often unreliable or of poor quality. Additionally, many families engage in informal economic activities that do not register with standard income data - a common phenomenon in Ghana - which can serve to render traditional measures of poverty invalid. In response to these problems, the DHS began collecting data for a 'wealth score' in 2004. This index: ${ }^{(37)}$

is a composite measure of the cumulative living standard of a household. It is calculated using easyto-collect data on a household's ownership of selected assets, such as televisions and bicycles, materials used for housing construction, and types of water access and sanitation facilities. Generated with... principal components analysis, the wealth score places individual households on a continuous scale of relative wealth... Even in countries that collect [income] data, the DHS wealth index has outperformed the traditional indicators.

The wealth score is provided in the form of a continuous value as well as a categorical variable ('wealth index') that roughly divides the population into quintiles. The categorized value was employed in the present study.

Contextual variables included in the analysis were population density, poverty index $\left(\mathrm{P}_{0}\right)$, district-level literacy, proximity to health and school facilities, urbanization, percentage of the population who are migrants and ecological zone. Administrative districts were used in the present study to indicate context because they are the basic spatial units for most socio-economic, political and developmental decisions in Ghana and are the basic spatial units for the national census data and the GDHS 2008 population clusters. Regional and district codes embedded in the GDHS 2008 were used to determine the district of residence for each child in the sample. Data for population density (the population per square kilometre), the percentage urban, percentage migrant, percentage illiterate and the level of urbanization for each district were derived from the 2000 PHC. The $\mathrm{P}_{0}$ measures the proportion of the population in a given district that is poor and is intended to represent the general wealth of the district. Although this measure is widely used because of its ease of interpretation, it does not indicate the degree of poverty ${ }^{(38)}$. The GDHS 2008 child data were joined to ecological zones data in a geographical information system database using ArcGIS 9.3 software. The database join serves to assign each child in the study to an ecological zone based on their location.

\section{Analysis}

Data analysis was performed using the SPSS $20 \cdot 0$ for Windows statistical software package. All children aged 0-59 months with valid anthropometric measures were included, constituting a total of 2225 children. Since standard analysis of fixed-effects covariates for heightfor-age neglects the correlation structure and dependence in the hierarchically structured GDHS data, a two-level generalized linear mixed-modelling approach was employed, with level-1 represented by individual child characteristics and level-2 represented by the characteristics of the district in which children reside. The heightfor-age outcome of a child is therefore assessed as a function of child-level and district-level characteristics. This reduces the tendency to underestimate standard errors of fixed effects at the child level which inflates apparent significance of estimates.

A model that assesses the effects of only level-1 variables was first estimated for height-for-age (individual model). 
A separate model with only level-2 variables was then estimated (district model) before a final full model with both level-1 and level-2 variables was estimated. The coefficients of both fixed and random effects along with confidence intervals for $P<0.05$ as well as model summaries are reported.

The full model is specified by the general notation:

$$
Y=X \beta+Z u+\varepsilon,
$$

where $Y$ represents the height-for-age for an individual child, $X \beta$ the fixed-effect regressors and parameters, $Z u$ the regressors and random effects, and $\varepsilon$ the errors.

\section{Results}

\section{Sample characteristics}

The present study analysed the height measurements of 2225 children, $49 \cdot 6 \%$ of whom were female and $50 \cdot 4 \%$ male. The average age of a child in the sample was 29 months and more than $95 \%$ of all children had received part or all of the recommended vaccinations for their age. Children were breast-fed for an average of 16 months and $23 \%$ had height-for-age $<-2$ SD. Most children lived in rural areas (67\%) and in the forest ecological zone (44\%).

\section{Child-level characteristics and beight-for-age}

An individual-level model was estimated to examine their effects on the outcome. The results showed that the overall model $(F=23.738 ; P<0 \cdot 001)$ and seven variables including the age of the child $(F=48 \cdot 204$; $P<0 \cdot 001)$, vaccination status $(F=5.643 ; P=0 \cdot 004)$, the size of the child at birth $(F=11 \cdot 660 ; P<0 \cdot 001)$, months of breast-feeding $(F=58.292 ; P<0 \cdot 001)$, mother's BMI $(F=31.937 ; P<0.001)$ and possession of health insurance $(F=4.557 ; P=0 \cdot 033)$ were statistically significantly associated with height-for-age. Many child-level characteristics did not achieve statistical significance in any of the models. These included the sex of the child, mother's education, size of the household and ethnicity. The results of the individual model are presented in Table 1.

Although the wealth status of the child's household did not appear significant in the traditional test of fixed effects for the overall model and individual effects, the poorest and poorer categories showed a statistically significant association with height-for-age in the parameter estimates for the overall model and individual effects. All other things being equal, we can expect the height-for-age of children from the poorest households to be $0.433 \mathrm{SD}$ $(P=0 \cdot 009)$ lower than the height-for-age of a child from the richest household. Similarly, the height-for-age of a child from a household in the poorer wealth quintile is

Table 1 Results of the individual model: individual-level correlates with height-for-age in Ghanaian children aged 0-59 months ( $n$ 2225), 2008

\begin{tabular}{|c|c|c|c|c|}
\hline Fixed effects & Estimate & SE & $P$ value & $95 \% \mathrm{Cl}$ \\
\hline Intercept & -0.088 & 0.040 & $0 \cdot 029^{*}$ & $-0.167,-0.091$ \\
\hline Child's age (months) & -0.015 & 0.002 & $0 \cdot 000^{*}$ & $-0.020,-0.011$ \\
\hline \multicolumn{5}{|l|}{ Vaccination status } \\
\hline Not vaccinated & +0.048 & 0.014 & $0 \cdot 001^{*}$ & $+0 \cdot 200,+0 \cdot 760$ \\
\hline Partially vaccinated & +0.024 & 0.078 & $0 \cdot 761$ & $-0.129,+0 \cdot 176$ \\
\hline \multicolumn{5}{|l|}{ Size of child at birth } \\
\hline Very large & +0.080 & $0 \cdot 123$ & $0 \cdot 000^{*}$ & $+0.056,+0.104$ \\
\hline Larger than average & +0.514 & $0 \cdot 124$ & $0 \cdot 000^{*}$ & $+0.027,+0.768$ \\
\hline Average & +0.553 & $0 \cdot 123$ & $0.000^{*}$ & $+0.299,+0.806$ \\
\hline $\begin{array}{l}\text { Smaller than average } \\
\text { Very small (ref.) }\end{array}$ & $+0 \cdot 360$ & $0 \cdot 133$ & $0 \cdot 007^{*}$ & $+0.094,+0.621$ \\
\hline Months of breast-feeding & -0.037 & 0.005 & $0.000^{*}$ & $-0.046,-0.027$ \\
\hline Mother's BMI & +0.039 & 0.007 & $0 \cdot 000^{*}$ & $+0.025,+0.052$ \\
\hline \multicolumn{5}{|l|}{ Health insurance } \\
\hline No & -0.165 & 0.078 & $0.033^{*}$ & $-0.032,-0.013$ \\
\hline Yes (ref.) & & & & \\
\hline \multicolumn{5}{|l|}{ Wealth quintile } \\
\hline Poorest & -0.433 & $0 \cdot 166$ & $0 \cdot 009^{*}$ & $-0.759,-0.011$ \\
\hline Poorer & -0.385 & $0 \cdot 140$ & $0 \cdot 006^{\star}$ & $-0.658,-0.111$ \\
\hline Middle & -0.248 & $0 \cdot 126$ & $0 \cdot 050$ & $-0.496,+0.000$ \\
\hline Richer & -0.205 & 0.011 & 0.064 & $-0.421,+0.012$ \\
\hline \multicolumn{5}{|l|}{ Richest (ref.) } \\
\hline \multicolumn{5}{|l|}{ Random effects } \\
\hline Intercept & 0.061 & 0.026 & $0 \cdot 017^{\star}$ & $0.027,0.140$ \\
\hline Residuals & $2 \cdot 001$ & 0.062 & $0 \cdot 000^{\star}$ & $1 \cdot 883,2 \cdot 126$ \\
\hline \multicolumn{5}{|l|}{ Model fit statistics } \\
\hline-2 log likelihood & $7994 \cdot 571$ & & & \\
\hline $\mathrm{AIC}$ & $7998 \cdot 587$ & & & \\
\hline $\mathrm{BIC}$ & $8009 \cdot 966$ & & & \\
\hline
\end{tabular}

ref., reference category; AIC, Akaike information criterion; BIC, Bayesian information criterion.

${ }^{\star} P<0 \cdot 05$. 
Table 2 Results of the district model: district-level correlates with height-for-age in Ghanaian children aged 0-59 months ( $n$ 2225), 2008

\begin{tabular}{|c|c|c|c|c|}
\hline Fixed effects & Estimate & SE & $P$ value & $95 \% \mathrm{Cl}$ \\
\hline Intercept & $-0 \cdot 17640$ & 0.43569 & 0.686 & $-1 \cdot 03180,+0 \cdot 67800$ \\
\hline Population density & +0.00004 & 0.00003 & $0 \cdot 170$ & $-0.00002,+0.00009$ \\
\hline Poverty index $\left(\mathrm{P}_{0}\right)$ & $-0 \cdot 75794$ & 0.49211 & $0 \cdot 124$ & $-1 \cdot 72298,+0 \cdot 20710$ \\
\hline$\%$ of population within $10 \mathrm{~km}$ of hospital & -0.00158 & 0.00242 & 0.514 & $-0.00633,+0.00317$ \\
\hline$\%$ of population within $10 \mathrm{~km}$ of clinic & -0.00288 & 0.00277 & 0.299 & $-0.00831,-0.00255$ \\
\hline$\%$ of population within $5 \mathrm{~km}$ of school & +0.00283 & 0.00217 & $0 \cdot 191$ & $-0.00142,+0.00708$ \\
\hline$\%$ of illiterate population & -0.00289 & 0.00481 & 0.548 & $-0.01233,+0.00654$ \\
\hline$\%$ of urban population & +0.00271 & 0.00211 & $0 \cdot 199$ & $-0.00143,+0.00684$ \\
\hline$\%$ of migrant population & -0.00422 & 0.00432 & 0.329 & $-0.01268,+0.00425$ \\
\hline \multicolumn{5}{|l|}{ Ecological zone } \\
\hline Eastern Guinea Forest & $+0 \cdot 18087$ & $0 \cdot 24194$ & $0 \cdot 455$ & $-0.29357,+0.65532$ \\
\hline West Sudanian Savannah & $-0 \cdot 30840$ & $0 \cdot 17665$ & 0.081 & $-0.65481,+0.03801$ \\
\hline $\begin{array}{l}\text { Guinea Forest-Savannah Mosaic } \\
\text { Central African Mangrove (ref.) }\end{array}$ & $-0 \cdot 26686$ & $0 \cdot 17540$ & $0 \cdot 128$ & $-0.61083,+0.07711$ \\
\hline \multicolumn{5}{|l|}{ Random effects } \\
\hline Intercept & 0.074 & 0.031 & $0 \cdot 018^{*}$ & $0.032,0.168$ \\
\hline Residuals & $2 \cdot 340$ & 0.072 & $0 \cdot 000^{*}$ & $2 \cdot 203,2 \cdot 485$ \\
\hline \multicolumn{5}{|l|}{ Model fit statistics } \\
\hline-2 log likelihood & $8265 \cdot 726$ & & & \\
\hline AIC & $8269 \cdot 731$ & & & \\
\hline $\mathrm{BIC}$ & $8281 \cdot 130$ & & & \\
\hline
\end{tabular}

ref., reference category; AIC, Akaike information criterion; BIC, Bayesian information criterion. ${ }^{*} P<0.05$.

$0 \cdot 385 \mathrm{SD}(P=0 \cdot 006)$ lower than the height-for-age of a child from the richest household.

\section{District-level characteristics and beight-for-age}

A separate model including only district-level variables was estimated for height-for-age to examine the relationship between contextual variables and children's nutritional outcome. None of the eleven variables included in the model was significantly associated with the height-for-age outcome for children in Ghana (Table 2), even though the overall model intercept $(F=3 \cdot 814 ; P<0 \cdot 001)$ was significant.

\section{Full model for beight-for-age in Ghana}

The full model analysed both child-level and district-level variables simultaneously, uncovering some differences from the first two models. Notably, in the full model, population density showed a statistically significant association with height-for-age outcome among children in Ghana. The fixed-and random-effect estimates for heightfor-age are presented in Table 3.

\section{Discussion}

Consistent with other studies ${ }^{(35,39)}$, the present study observed that children's age was significantly associated with lower height-for-age values. As ample previous research has shown, this finding could be attributed to the challenges of transitioning from breast-feeding to more solid foods and drinking water. Another factor may be older children's ability to explore their environment, giving them more exposure to infections that compromise their nutritional status ${ }^{(20)}$.
Curiously, children who were not vaccinated were more likely to have a higher height-for-age status, contradicting previous work which suggests that vaccination, which should protect children against infectious disease, serves to improve nutritional outcomes ${ }^{(29)}$. Additional investigation might uncover some explanation for this finding.

Children's weight at birth, in both the individual and full models, emerged as one of the strongest predictors of early growth. Birth weight is often used to estimate the quality of prenatal care. Previous work has demonstrated that good prenatal care is essential for survival among very young children in poor contexts ${ }^{(40)}$, and this may be viewed as evidence that prenatal care may similarly have an impact on nutritional status later in life.

Studies also show that an initial period of exclusive breast-feeding is essential to lower the risk of nutritional deficiency and infectious disease, after which supplementary foods should be gradually introduced. The present study found prolonged breast-feeding to be associated with poorer nutritional status. The negative association of lengthy breast-feeding with children's nutritional status probably reflects failure of optimal complementary feeding. This may in turn indicate the inability of households to provide supplemental foods ${ }^{(25)}$ and inappropriate child-feeding practices that could be addressed through education.

The present work found that the $40 \%$ of children living in households with some form of health insurance had a better height-for-age outcome. Other work has found that forms of protection, such as social capital, can serve to protect families against economic shocks, ultimately benefiting nutritional status ${ }^{(41)}$. Health insurance may similarly serve to protect poor families from such shocks. 
Table 3 Results of the full model: correlates with height-for-age in Ghanaian children aged 0-59 months ( $n$ 2225), 2008

\begin{tabular}{|c|c|c|c|c|}
\hline Fixed effects & Estimate & SE & $P$ value & $95 \% \mathrm{Cl}$ \\
\hline Child's age (months) & -0.016 & 0.002 & $<0.001^{*}$ & $-0.012,-0.011$ \\
\hline \multicolumn{5}{|l|}{ Vaccination status } \\
\hline Not vaccinated & 0.485 & $0 \cdot 142$ & $0.001^{*}$ & $+0.207,+0.763$ \\
\hline $\begin{array}{l}\text { Partially vaccinated } \\
\text { Fully vaccinated (ref.) }\end{array}$ & 0.026 & 0.078 & $0 \cdot 753$ & $-0 \cdot 129,+0 \cdot 179$ \\
\hline \multicolumn{5}{|l|}{ Size of child at birth } \\
\hline Very large & 0.805 & $0 \cdot 122$ & $<0.001^{*}$ & $+0.566,+1.045$ \\
\hline Larger than average & 0.521 & $0 \cdot 123$ & $<0.001^{*}$ & $+0.279,+0.763$ \\
\hline Average & 0.565 & $0 \cdot 128$ & $<0.001^{*}$ & $+0.314,+0.815$ \\
\hline $\begin{array}{l}\text { Smaller than average } \\
\text { Very small (ref.) }\end{array}$ & 0.355 & $0 \cdot 129$ & $0 \cdot 006^{\star}$ & $+0.011,+0.609$ \\
\hline Months of breast-feeding & -0.036 & 0.005 & $<0.001^{*}$ & $-0.046,-0.027$ \\
\hline Mother's BMI & 0.039 & 0.007 & $<0.001^{*}$ & $+0.025,+0.052$ \\
\hline \multicolumn{5}{|l|}{ Health insurance } \\
\hline $\begin{array}{l}\text { No } \\
\text { Yes (ref.) }\end{array}$ & $-0 \cdot 183$ & 0.07775 & $0 \cdot 018^{*}$ & $-0.019,-0.030$ \\
\hline \multicolumn{5}{|l|}{ Wealth quintile } \\
\hline Poorest & -0.379 & $0 \cdot 17967$ & $0.033^{*}$ & $-0.730,-0.029$ \\
\hline Poorer & -0.333 & 0.15323 & $0 \cdot 028^{*}$ & $-0.633,-0.033$ \\
\hline Middle & -0.194 & $0 \cdot 13382$ & 0.138 & $-0.457,+0.068$ \\
\hline Richer & -0.169 & $0 \cdot 12093$ & $0 \cdot 159$ & $-0.406,+0.068$ \\
\hline Richest (ref.) & & & & \\
\hline Population density & 0.00007 & 0.00003 & $0.024^{*}$ & $+0.00001,+0.00013$ \\
\hline \multicolumn{5}{|l|}{ Random effects } \\
\hline Intercept & 0.074 & 0.029 & $0 \cdot 012^{*}$ & $0.034,0.162$ \\
\hline Residuals & 1.996 & 0.062 & $0.000^{\star}$ & $1 \cdot 878,2 \cdot 121$ \\
\hline \multicolumn{5}{|l|}{ Model fit statistics } \\
\hline-2 log likelihood & $8002 \cdot 975$ & & & \\
\hline AIC & $8006 \cdot 980$ & & & \\
\hline $\mathrm{BIC}$ & $8018 \cdot 350$ & & & \\
\hline
\end{tabular}

ref., reference category; AIC, Akaike information criterion; BIC, Bayesian information criterion. ${ }^{*} P<0 \cdot 05$.

Household wealth was also related to height-for-age. Poverty often results in inadequate diet, poor sanitation and greater exposure to pathogens, and low access to vaccinations and basic medical care. Forty-five per cent of Ghanaians live on less than \$US 1 per day and while the highest fifth of households receive nearly half of all income, the poorest two-fifths receive only $16 \%$ of the total income $^{(42)}$. Improving children's health and nutritional status may ultimately require addressing economic inequalities and making services more accessible to the poor.

Population density, a contextual variable modelled at the district level, was significantly associated with more favourable nutritional outcomes after accounting for individual wealth and other contextual variables, such as district-wide poverty and urbanization, suggesting that processes related to settlement patterns are related to nutrition. It is possible that a tight population network, large nearby neighbourhoods or communities, can enable the kind of social capital that serves to provide families and their children with a more consistent source of nutrition and nutritional information ${ }^{(41,43)}$. Apart from population density, none of the socio-economic or biophysical contextual variables bore a significant relationship with childhood height-for-age in the final model, suggesting that the most critical scale at which mechanisms behind malnutrition are played out is at the individual and household levels.
As with any analysis of secondary data, some limitations should be noted with the present work. The study was based on diverse sources of secondary data which were not specifically designed for examining the relationships analysed here. In spite of these limitations, the large size and representativeness of the secondary data used in the study made possible the kinds of statistical analyses conducted here. The study findings can potentially assist stakeholders by providing a better understanding of the diverse array of factors that influence children's nutritional outcome in Ghana.

\section{Future work}

The study of children's nutrition has been limited, to a degree, by division into diverse disciplines, with many social scientists focused on individual- and householdlevel factors, nutritionists concerned with hereditary and gender differences, and soil and climate scientists fixated on the potential impact of climate and soil on agricultural sustainability and food production. While these fields of enquiry are conceptually linked by, for instance, the UNICEF framework, few studies systematically assess this variety of factors simultaneously. Although the present study attempts to close this gap, constructing dynamic and engaged interdisciplinary research that involves diverse spheres of knowledge would not be an insignificant future undertaking for work 
on children's well-being. Such interdisciplinary research might pave the way for more focused interventions in children's nutrition in developing countries.

Consideration should also be given to the strategies that children, households and communities utilize to solve socio-economic problems that impact children's nutritional outcomes. Children's families and communities are often required to make creative choices to guarantee favourable nutritional outcomes. Understanding the challenges and coping mechanisms that children, their households and communities use can provide important insights into how policy should be oriented.

Future research should also address the mechanisms through which childhood nutrition and different types of environments are connected. Understanding these mechanisms is crucial to the design of district-based interventions because these processes are more amenable to change than entrenched structural properties of communities (e.g. concentrated poverty). Although the present study does not investigate these mechanisms, the findings here provide limited evidence that area effects play a role in growth. Most of the contextual variables, however, did not achieve significance in the multivariate analyses discussed here, some of which have been widely reported to be associated with children's nutritional outcomes in different contexts. Future research could seek explanations for the lack of association with children's nutritional outcomes in the Ghanaian context.

\section{Acknowledgements}

This research received no specific grant from any funding agency in the public, commercial or not-for-profit sectors. The authors declare that there is no conflict of interest with the publication of this work. This project was completed by the authors as part of their dissertation work. E.N. conducted the initial analytical work, P.A. drafted the initial version of the manuscript, and both authors contributed to the final version. The authors would like to acknowledge their dissertation advisor, Connie Weil, for guidance in this project.

\section{References}

1. Pradilla A (1991) The geographic distribution of malnutrition. In Infant and Child Nutrition Worldwide: Issues and Perspectives, pp. 21-30 [FT Falkner, editor]. Boca Raton, FL: CRC Press.

2. UNICEF (2011) Undernutrition. http://www.unicef.org/ progressforchildren/2006n4/undernutritiondefinition.html (accessed February 2011).

3. Benson T \& Shekar M (2006) Trends and issues in child undernutrition. In Disease and Mortality in Sub-Saharan Africa, 2nd ed., pp. 87-106 [D Jamison, RG Feacham, MW Makgoba et al., editors]. Washington, DC: World Bank Publications.

4. UNICEF (2009) Global Child Mortality Continues to Fall. http://www.unicefusa.org/news/releases/global-childmortality.html (accessed February 2011).
5. Ghana Statistical Service (2009) Ghana Demographic and Health Survey, 2008. Accra/Calverton, MD: Ghana Statistical Service/ICF Macro.

6. Materechera SA (2010) Utilization and management practices of animal manure for replenishing soil fertility among smallscale crop farmers in semi-arid farming districts of the North West Province, South Africa. Nutr Cycl Agroecosys 87, 415-428.

7. Stepniewski W, Horn R \& Martyniuk S (2002) Managing soil biophysical properties for environmental protection. Agric Ecosyst Environ 88, 175-181.

8. Dang S, Yan H, Yamamoto S et al. (2004) Poor nutritional status of younger Tibetan children living at high altitudes. Eur J Clin Nutr 58, 938-946.

9. Ghosh A \& Kshatriya GK (2009) Anthropometric and body composition characteristics among preschool children of Coastal, Himalayan and Desert Ecology in India. Anthropol Anz 67, 229-236.

10. Legg C (2008) A Spatial Analysis of Child Nutrition in West Africa. ReSAKSS Working Paper no. 23. Ibadan, Nigeria: ReSAKSS-West Africa.

11. Balk D, Storeygard A, Levy M et al. (2005) Child hunger in the developing world: an analysis of environmental and social correlates. Food Policy 30, 584-611.

12. Anthamatten P (2007) Childhood malnutrition in Bolivia: an examination of associations with individual, household, and contextual variables. Dissertation, University of Minnesota.

13. Dickinson N, Macpherson G, Hursthouse AS et al. (2009) Micronutrient deficiencies in maternity and child health: a review of environmental and social context and implications for Malawi. Environ Geochem Health 31, 253-272.

14. Prost M-A, Jahn A, Floyd S et al. (2008) Implication of new WHO growth standards on identification of risk factors and estimated prevalence of malnutrition in rural Malawian infants. PLOS ONE 3, e2684.

15. Measure DHS (2010) DHS methodology. http://www. measuredhs.com/aboutsurveys/dhs/methodology.cfm (accessed May 2010).

16. World Wildlife Fund (2001) Ecoregions - Terresrial Ecoregions. http://www.worldwildlife.org/science/ecoregions/ item1267.html (accessed May 2010).

17. Olson DM, Dinerstein E, Wikramanayake ED et al. (2001) Terrestrial ecoregions of the worlds: a new map of life on Earth. Bioscience 51, 933-938.

18. Fotso JC (2007) Urban-rural differentials in child malnutrition: trends and socioeconomic correlates in sub-Saharan Africa. Health Place 13, 205-223.

19. Frost MB, Forste R \& Haas DW (2005) Maternal education and child nutritional status in Bolivia: finding the links. Soc Sci Med 60, 395-407.

20. Hong R (2007) Effect of economic inequality on chronic childhood undernutrition in Ghana. Public Health Nutr 10, 371-378.

21. Hong R \& Mishra V (2006) Effect of wealth inequality on chronic under-nutrition in Cambodian children. $J$ Health Popul Nutr 24, 89-99.

22. Victora CG (1992) The association between wasting and stunting - an international perspective. J Nutr 122, $1105-1110$.

23. World Health Organization (2006) WHO Child Growth Standards: Length/Height-for-Age, Weight-for-Age, Weightfor-Length, Weight-for-Height and Body Mass Index-forAge: Methods and Development. Geneva: WHO.

24. Fotso JC \& Kuate-Defo B (2005) Socioeconomic inequalities in early childhood malnutrition and morbidity: modification of the household-level effects by the community SES. Health Place 11, 205-225.

25. Van de Poel E, Hosseinpoor AR, Jehu-Appiah C et al. (2007) Malnutrition and the disproportional burden on the poor: the case of Ghana. Int J Equity Health 6, 21. 
26. Khatib IMD \& Elmadfa I (2009) Poor nutritional health of Bedouin preschool children in Jordan: the irony of urbanization. Ann Nutr Metab 54, 301-309.

27. Wamani H, Astrom AN, Peterson S et al. (2006) Predictors of poor anthropometric status among children under 2 years of age in rural Uganda. Public Health Nutr 9, 320-326.

28. Wamani H, Astrom AN, Peterson S et al. (2007) Boys are more stunted than girls in sub-Saharan Africa: a metaanalysis of 16 demographic and health surveys. BMC Pediatr 7, 17.

29. Bloss E, Wainaina F \& Bailey RC (2004) Prevalence and predictors of underweight, stunting, and wasting among children aged 5 and under in western Kenya. J Trop Pediatr 50, 260-270.

30. Faruque ASG, Ahmed AMS, Ahmed T et al. (2008) Nutrition: basis for healthy children and mothers in Bangladesh. J Health Popul Nutr 26, 325-339.

31. Wachs TD, Creed-Kanashiro H, Cueto S et al. (2005) Maternal education and intelligence predict offspring diet and nutritional status. J Nutr 135, 2179-2186.

32. Singh GCP, Nair M, Grubesic RB et al. (2009) Factors associated with underweight and stunting among children in rural terai of Eastern Nepal. Asia Pac J Public Health 21, 144-152.

33. Bronte-Tinkew J \& DeJong G (2004) Children's nutrition in Jamaica: do household structure and household economic resources matter? Soc Sci Med 58, 499-514.

34. World Bank (2002) Poverty and Nutrition in Bolivia: $A$ World Bank Country Study. Washington, DC: World Bank.
35. Bomela NJ (2009) Social, economic, health and environmental determinants of child nutritional status in three Central Asian Republics. Public Health Nutr 12, 1871-1877.

36. Uthman OA, Moradi T \& Lawoko S (2009) The independent contribution of individual-, neighbourhood-, and countrylevel socioeconomic position on attitudes towards intimate partner violence against women in sub-Saharan Africa: a multilevel model of direct and moderating effects. Soc Sci Med 68, 1801-1809.

37. Demographic and Health Surveys (2006) Description of the Demographic and Health Surveys Individual Recode Data File. http://www.measuredhs.com/zip/recodhs.zip (accessed April 2010).

38. Coulombe H (2005) Ghana Census-based poverty map: district and sub-district level results 1. World July issue, $1-28$.

39. Colecraft EK, Marquis GS, Bartolucci AA et al. (2004) A longitudinal assessment of the diet and growth of malnourished children participating in nutrition rehabilitation centres in Accra, Ghana. Public Health Nutr 7, 487-494.

40. Hong R (2006) Effect of multiple birth on infant mortality in Bangladesh. J Paediatr Child Health 42, 630-635.

41. Carter MR \& Maluccio JA (2003) Social capital and coping with economic shocks: an analysis of stunting of South African children. World Dev 31, 1147-1163.

42. UNICEF (2006) At a Glance: Ghana. http://www.unicef. org/infobycountry/ghana.html (accessed February 2010).

43. Alderman H, Hentschel J \& Sabates R (2003) With the help of one's neighbors: externalities in the production of nutrition in Peru. Soc Sci Med 56, 2019-2031. 